\title{
Ruhsal Bozukluklarda Gevşeme Eğitiminin Ağrı, Yorgunluk Ve Uyku Üzerine Etkisinin İncelenmesi
}

Investigation of the Effect of Relaxation Training on Pain, Fatigue and Sleep in Mental Disorders

\author{
Zeynep KOLIT'1 , Gamze EKİCi² ${ }^{2}$ A. Elif ANIL YAĞCIOĞLU³ \\ ${ }_{1}^{1}$ Erg. Hacettepe Üniversitesi, Sağlık Bilimleri Fakültesi, Ergoterapi Bölümü, Ankara, Türkiye \\ ${ }^{2}$ Prof. Dr. Hacettepe Üniversitesi, Sağlık Bilimleri Fakültesi, Ergoterapi Bölümü, Ankara, Türkiye \\ 3 Prof. Dr. Hacettepe Üniversitesi, Tıp Fakültesi, Ruh Sağlığı ve Hastalıkları Anabilim Dalı, Ankara, Türkiye
}

\section{öz}

Amaç: Ruhsal bozukluklar ciddi emosyonel, davranışsal ve fiziksel sağlık sorunlarına neden olabilir. Fiziksel sorunlar uyku bozukluğu, ağrı, uyuşukluk, yorgunluk gibi belirtiler içermektedir. Bu çalışma ruhsal bozukluklarda gevşeme eğitiminin ağrı, yorgunluk şiddeti ve uyku sorununa etkisini incelemek

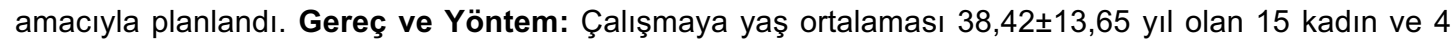
erkek olmak üzere 19 ruhsal bozukluğu olan gönüllü birey dâhil edildi. Görsel Analog Skala ile ağrı, yorgunluk şiddeti ve uyku sorunu müdahale öncesi ve sonrası değerlendirildi. Müdahale programında zihinde canlandırma, solunum tekniği, ilerleyici kas gevşeme ve postür eğitimini içeren gevşeme eğitimi 5 hafta boyunca haftada $2 \mathrm{kez}$ verildi. Ayrıca katılımcılara gelmedikleri günler için ev programı verildi. Sonuçlar: Bireylerin ağrı düzeyi $(p=0,007)$, yorgunluk şiddeti $(p=0,001)$ ve uyku sorunu $(p=0,001)$ eğitim öncesi ve sonrası karşıllaştırılığında istatistiksel olarak anlamlı farklııklar bulunmuştur. Tartışma: Çalışmadan elde edilen veriler doğrultusunda ruhsal bozukluğu olan bireylerde gevşeme eğitiminin ağrı, yorgunluk ve uyku sorununun giderilmesi açısından iyileştirici etkileri ortaya koyulmuştur. Ruhsal bozuklukların rutin tedavisine gevşeme eğitiminin dâhil edilmesi faydalı olacaktır. Uzun dönem takibin yapıldığı, teşhis açısından homojen grupların dâhil edildiği ileri çalışmalara ihtiyaç vardır.

Anahtar Kelimeler: Mental hastalıklar; Kas gevşemesi; Ağrı; Yorgunluk; Uyku

\section{ABSTRACT}

Purpose: Mental disorders can cause serious emotional, behavioral and physical health problems. Physical problems include sleep disorder, pain, numbness, fatigue. This study was planned to investigate the effect of relaxation training on pain, fatigue severity and sleep problems in mental disorders. Material and Methods: The study included 19 volunteers with mental disorders, 15 females and 4 males with a mean age of $38.42 \pm 13.65$ years. Visual Analogue Scale was used to assess pain, fatigue severity and sleep problems before and after the intervention. In the intervention program, relaxation training which included visualization, breathing technique, progressive muscle relaxation and posture training was given twice a week for 5 weeks. Participants were also given home program for the days they didn't come. Results: Statistically significant differences were found between the pre-and post-training levels of the individuals' pain levels $(p=0.007)$, fatigue severity $(p=0.001)$ and sleeping problem $(p=0.001)$. Conclusion: According to the data obtained from this study, relaxation training has healing effects in terms of reducing pain, fatigue and sleep problems in individuals with mental disorders. It would be useful to include relaxation training in the routine treatment of mental disorders. Further studies are needed in which long-term follow-up is performed and homogeneous groups are included regarding diagnosis.

Keywords: Mental disorders; Muscle relaxation; Pain; Fatigue; Sleep 
Ruhsal bozukluklar depresyon, bipolar affektif bozukluk, şizofreni ve diğer psikozlar da olduğu gibi genellikle anormal düşüncelerin, algıların, duyguların, davranışların ve başkalarıyla olan bozuk ilişkilerin bir kombinasyonu ile karakterizedir (Dünya Sağlık Örgütü, 2017).

Dünyada her dört kişiden biri yaşamı boyunca bir ya da daha fazla ruhsal ve davranışsal sorun yaşamaktadır (Durukan, İlhan, Bumin ve ark., 2011). Dünyada psikolojik ve fizyolojik açıdan kayba, erken ölüme yol açan on hastalıktan beşi ruhsal bozukluklar kaynaklıdır (Gültekin, 2010).

Türkiye'de de ruhsal bozukluklar sık karşılaşılan sorunlarındandır. Ulusal düzeyde hastalık yükü nedenlerinin temel hastalık gruplarına göre kardiyovasküler problemlerden sonra ruhsal hastalık grubunun ikinci sırada yer aldığı görülmektedir (T.C.Sağlık Bakanlığı, 2011). Toplumumuzda psikiyatrik yardım gerektiren ruhsal sorunların \% 20 'nin üzerinde bir yaygınlığa sahip olduğu belirtilmektedir (Kurt ve Akbaba, 2018).

Ruhsal bozukluklar duygusal yük, stresli yaşam deneyimleri ve baş edilmesi gereken çeşitli durumları içerebilir (Sağbaş, 2008). Birey fiziksel, psikolojik ya da psiko-sosyal stres uyaranlarına maruz kaldığında; içinde bulunduğu ortama, hazır oluşuna, uyaranı algılama şekline, daha önceki yaşantı ve deneyimlerine göre fizyolojik, psikolojik ve davranışsal olarak "savaş ya da kaç" tepkileri vermektedir (Aydın ve İmamoğlu, 2001).

Fizyolojik düzeyde; yüksek tansiyon, ağrı, kalp atışlarında artma, ellerde titreme gibi bulgular görülür. Davranış düzeyinde ise; yorgunluk, bitkinlik, el-kol koordinasyonunda bozukluklar, kekeleme, değişken ve tahmin edilemeyen davranışlar, performansta azalma, başladığı işi bitirmede sorunlar, konsantrasyon bozuklukları, uykusuzluk ya da derin uykuya dalamama, beslenme alışkanlıklarında değişiklikler, sigara ve alkol alımında artış gibi tepkiler oluşmaktadır (Aydın ve ark., 2001; Ergül, 2012).

Baş etme becerilerini geliştirmek amacıyla farmakolojik ve farmakolojik olmayan yaklaşımlardan yardım alınmaktadır. Farmakolojik olmayan yaklaşımlar içerisinde bilişsel, akılcı-duygusal, problem odaklı, duygu odaklı ve düşünce odaklı yaklaşımlar kullanılabilir. Bu yaklaşımların yanı sıra meditasyon, otojenik eğitim, imajinasyon, solunum, postür egzersizleri ve ilerleyici kas gevşeme tekniğini içeren gevşeme teknikleri, fiziksel aktivite, düzenli beslenme, sosyal faaliyetlere katılma, zaman yönetimi, zihinsel düzenleme ve davranışsal yaklaşımlar gibi yöntemlerden de yararlanılmaktadır
(Bozhüyük, Özcan, Kurdak ve ark., 2012).

Solunum, gevşeme ve iyi olma hali için oldukça önemli bir rol oynamaktadır. Bireylerin başa çıkma yöntemlerini uygulamaya başlarken ilk aşamada solunuma odaklanmasının, en kolay ve etkili başa çıkma yollarından biri olduğu belirtilmektedir. (Körükcü ve Kukulu, 2015). Başa çıkma yollarından biri olan postüral egzersizler de, çeşitli hastalıkların tedavisinde kullanımasının yanı sıra ruhsal hastalıklara sahip bireylerin tedavisinde de önemli bir yer almaktadır (Çelebi, 2016). Gevşeme tekniklerinin, stres ve daha başka rahatsızlıklarla başa çıkmada başvurulan ilk adımlardan birisi olduğu bilinmektedir. Edmund Jacobson tarafından tanımlanmış olan ilerleyici kas gevşeme eğitiminin, büyük iskelet kas gruplarının sırasıyla gerilmesi ve gevşetilmesinden oluşan ruhsal ve bedensel farkındalığı sağlayarak gevşemeyi hedefleyen bir yaklaşım olduğu belirtilmektedir. Otonom ve santral sinir sisteminin uyarımasını azalttığı ve parasempatik sinir sisteminin aktivitesini artırdığı belirtilmektedir (Genç ve Oğuz, 2018).

Ruh ve beden sağlığını korumak, üretken ve verimli bir yaşam sürdürebilmek için baş etme becerilerinin geliştirilmesi gereklidir (Can, 2013). Ruhsal bir hastalık, diğer ruhsal ya da bedensel hastalıklara eşlik edebilir. Ruhsal bozukluklar toplumda yaygın olarak görülmeleri, kronikleşme eğilimi göstermeleri, en az diyabet, hipertansiyon ve artrit gibi bedensel hastalıklar kadar yeti kaybı ile sonuçlanabilmeleri ve iş gücü/günü kayıplarına sebep olmaları nedeniyle öncelikle ele alınması zorunlu hastalıklardandır (Ocaktan, Özdemir ve Akdur, 2004).

Ruhsal hastalıkların yaşamın fiziksel, psikolojik, mesleki ve sosyal alanları üzerinde olumsuz etkileri olduğu bilinmektedir. Matcham ve ark.'larının (2014) yaptığı sistematik derlemeye göre gevşeme eğitiminin hipertansiyon, kalp hastaları, diyabetik ülser, kanser gibi fiziksel hastalıklara sahip bireylerde daha çok uygulandığı görülmüştür (Matcham, Rayner, Hutton ve ark., 2014). Ergoterapistlerin, ruhsal hastalığa sahip olan bireylerin intiyaçları doğrultusunda bakım sağlarken kanıta dayalı yöntemler kullanmaları gerektiği belirtilmiştir (D'Amico, Jaffe ve Gardner, 2018). Ruhsal hastalıkların tedavisinde öncelikle ruhsal belirtilere odaklanılırken ağrı, yorgunluk, uyku gibi fiziksel bulgulara yönelik müdahale konusunda az sayıda çalışma olduğu görülmüştür. Bu nedenlerle çalışmamız ruhsal hastalıklarda gevşeme eğitiminin ağrı, yorgunluk ve uyku üzerine etkisinin incelenmesi amacıyla planlanmıştır. 


\section{GEREÇ VE YÖNTEM}

Çalışma 2018 yılında, Hacettepe Üniversitesi, Sağık Bilimleri Fakültesi, Ergoterapi Bölümü'ne başvuran, şizofreni, bipolar, obsesif kompülsif bozukluk ve major depresyon tanısı olan, Görsel Analog Skalasına (GAS) göre ağrı, yorgunluk ve uyku sorunlarından birinde en az $1^{\prime \prime} i$ işaretleyen gönüllü bireylerle yapılmıştır. Çalışma bire bir görüşme şeklinde gerçekleştirilmiştir. Bu çalışma Helsinki Deklarasyonuna uygun olarak yürütülmüş, çalışmaya katılan tüm olgular değerlendirme öncesi bilgilendirilerek gönüllü olduklarına yönelik onam formu imzalatılmıştır.

Çalışmaya, klinik değerlendirme sonucu ruhsal bozukluklardan herhangi bir tanısı olan, 18 ile 65 yaş aralığında, GAS'a göre ağrı, yorgunluk ve uyku sorunlarından birinde en az $1^{\prime} i$ işaretleyen, başka bilinen herhangi bir hastalığın olmayan bireyler dâhil edilmiştir. Çalışmaya 25 gönüllü birey katılmıştır ancak dâhil edilme kriterlerine uymama ve eğitimi yarıda bırakma gibi nedenlerle çalışma 19 kişiyle tamamlanmıştır (Şekil 1). 19 kişiden, 9'u major depresyon, 6'sı şizofren, 2'si bipolar ve 2'si OKB tanısı olan bireylerdir. Bireylerin sosyo-demografik bilgileri kaydedilmiştir. Görsel Analog Skala (GAS) ile ağrı, yorgunluk şiddeti, uyku sorunu, eğitim öncesi ve sonrası değerlendirilmiştir.

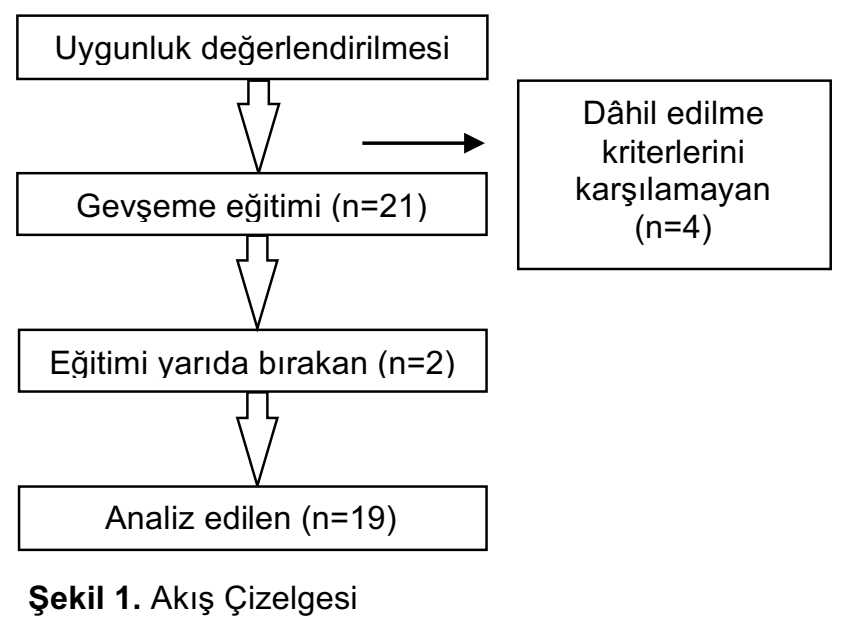

Müdahale öncesi değerlendirmelerin ardından bireye öncelikle doğru solunum, diyafragmatik ve göğüs solunumu yöntemleri gösterildikten sonra Jacopson'ın ilerleyici kas gevşeme tekniği uygulanmıştır. Sonrasında postür eğitimi verilmiştir. Bireylere yüz yüze haftada 2 gün, 5 hafta boyunca (10 seans) solunum tekniği, ilerleyici kas gevşeme ve postür eğitimi verilmiştir. Gevşeme eğitimi kapsamında zihinde canlandırma tekniği de kullanılmıştır. Seansların sonunda katılımcılara o seanstan öğrendiklerini tekrar etmeleri istenerek ev ödevi verilmiştir. Eğitim sonrası bireyler tekrar değerlendirilmiştir.

Sosyo-demografik Bilgi: Katılımcıların yaş (yıl), cinsiyet, kilo $(\mathrm{kg})$, boy $(\mathrm{m})$, vücut kütle indeksi $\left(\mathrm{kg} / \mathrm{m}^{2}\right)$, eğitim (yıl), medeni hali, çalışma durumu, alkol-sigara-madde kullanımı ve kiminle yaşadığı sorgulanmıştır.

Görsel Analog Skalası (GAS): Dünya literatüründe kabul gören GAS, güvenilir, kolay uygulanabilen bir testtir. Sayısal olarak ölçülemeyen bazı değerleri sayısal veri haline dönüştürmek için GAS kullanılmaktadır (Jensen, Fayers, Haugen ve ark., 2011; Aydın, Araz ve Asan, 2011). GAS, daha önceki çalışmalarda çoğunlukla, psikiyatri hastalarının sınıflandırılmasında, ağrıyı, ruh halini, yorgunluğu, solunumu, fonksiyonel kapasiteyi ve gerginliği ölçmede kullanılmıştır (Hasson ve Arnetz, 2005). Ayrıca, GAS'ın Likert skalasından daha iyi bir duyarlılığa (yani klinik olarak anlamlı bir değişikliği tespit etme yeteneğine) sahip olduğu ve aynı zamanda daha güvenilir ve geçerli olabileceği öne sürülmüştür (Ekici, Çelenay ve Büyükturan, 2017). Onhaus ve Adler'in en çok alıntı yapılan makalesinde, GAS'ın kişilerin gerçek deneyimlerine oldukça yakın değerlendirdiği belirtildi (Ohnhaus ve Adler, 1975).

Çalışmamızda ağrı, yorgunluk şiddeti ve uyku sorunu seviyeleri GAS kullanılarak incelenmiştir. 10 cm'lik bir çizginin iki ucuna değerlendirilecek parametrenin iki uç tanımı yazılarak ve kişiden bu çizgi üzerinde kendi durumunun nereye uygun olduğunu işaret etmesi istenir. Değerlendirme için bir uca "hiç ağrım yok-yorgun değilim-uyku sorunum yok", diğer uca "dayanılmaz ağrım var-çok şiddetli yorgunluğum var-çok ciddi uyku sorunum var" yazılarak o anki durumunu bu çizgi üzerinde işaretlemesi istenmiştir. 


\section{Müdahale Planı}

Gevşeme Eğitimi: Bireylere haftada 2 gün olmak üzere 5 hafta boyunca gevşeme eğitimi verilmiştir. Gevşeme eğitimi kapsamında zihinde canlandırma, solunum tekniği, ilerleyici kas gevşeme ve postür eğitimi verilmiştir. Seansın ilk başında doğru solunum tekniği öğretilmiştir. Solunum tekniği kapsamında diyafragmatik ve göğüs solunumu yöntemleri gösterilmiştir. Solunum tekniğinden sonra ilerleyici kas gevşeme tekniğiyle birlikte zihinde canlandırma tekniği ve sonrasında postür eğitimi verilmiştir. Kişiler sessiz, ortam ışığının kontrol edildiği, terapatik müzik eşliğinde seansa alınmıştır.

İlerleyici kas gevşeme tekniğinde gevşeme durumunun öğrenilmesi üzerinde durulmaktadır. İlerleyici kas gevşeme ile kişi, iskelet kaslarını kasar ve gevşetir. (Arslan ve Özdemir, 2015). Bu eğitimde, her seansta vücudun tamamının gevşemesinin sağlayacak iki ya da üç kas grubunun gevşemesi hedeflenir. Jacobson'ın bu yöntemiyle kas gruplarının kontrolü, gerilim ve anksiyetenin azaltılması amaçlanır (Otman, 2006).

İlerleyici kas gevşeme tekniği, vücutta tüm kaslarda gevşeme oluşuncaya kadar belli bir sıra dâhilinde distalden proksimale doğru ve tam tersi yönde büyük kasların bilinçli olarak kasılması ve gevşetilmesi işlemidir. Illerleyici kas gevşeme, kolay öğrenilebilen ve yan etkisi olmayan bir yöntemdir. Birey tüm bedenini gözden geçirerek kaslarını daha iyi tanır ve stres anında meydana gelen kas gerginliklerinin farkına daha çabuk vararak bilinçli olarak kaslarını gevşetmeyi öğrenmektedir (Alan, 2015).

Tablo 1. Bireylerin sosyo-demografik bilgileri.
Postür eğitiminde ise, postürün düzgünlüğüne yönelik boyun ve omuz kuşağını içeren terapatik yaklaşımlar solunumla kombine olacak şekilde katılımcılara öğretilmiştir. Solunum tekniği ve ilerleyici kas gevşeme tekniği sırt üstü gevşeme pozisyonunda yapılırken, postür eğitimi oturma pozisyonunda gerçekleştirilmiştir. Kişiler sırt üstü gevşeme pozisyonunda iken zihinsel odaklanmayı sağlayan zihinde canlandırma yöntemi de kullanılmıştır. Seanslar ortalama 30-45 dakika arasında sürecek şekilde gerçekleştirilmiştir.

\section{Istatistiksel Analiz}

İstatistiksel analizlerde 'SPSS 17 for Windows' istatistik programı kullanılmıştır. Katılımcıların sosyodemografik bilgileri gibi tanımlayıcı verilerde uygunluğuna göre frekans ve/veya Ortalama \pm

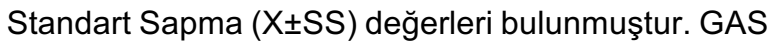
dan eğitim öncesi ve 10 seans sonrası elde edilen değerler için 'Wilcoxon Eşleştirilmiş Test' kullanılarak karşılaştırma yapılmıştır. İstatistiksel anlamlılık düzeyi $p<0,05$ olarak kabul edilmiştir.

\section{SONUÇLAR}

Çalışmaya yaşları 19-65 yıl arasında olan 15 kadın ve 4 erkek dâhil edildi. Ortalama yaşları $38.42 \pm 13.65$ yıl olarak kaydedilmiştir. Tablo 1'de bireylerin sosyo-demografik bilgileri verilmiştir. Katılımcıların hepsi aileleriyle birlikte yaşamaktadır. Bireylerin ağrı düzeyi $(p=0,007)$, yorgunluk şiddeti $(p=0,001)$ ve uyku sorununda $(p=0,001)$ eğitim öncesi ve sonrasında değerler karşılaştırıldığında istatistiksel olarak anlamlı farklılıklar bulunmuştur (Tablo 2).

\begin{tabular}{|c|c|}
\hline Sosyo-demografik bilgiler & n (\%) \\
\hline $\begin{array}{c}\text { Kadın } \\
\text { Erkek }\end{array}$ & $\begin{array}{l}15(78,9) \\
4(21,1)\end{array}$ \\
\hline $\begin{array}{r}\text { Major Depresyon } \\
\text { Şizofren } \\
\text { Bipolar } \\
\text { Obsesif Kompülsif Bozukluk }\end{array}$ & $\begin{array}{l}9(47,4) \\
6(31,6) \\
2(10,5) \\
2(10,5)\end{array}$ \\
\hline $\begin{array}{r}\text { Evli } \\
\text { Bekâr } \\
\text { Dul } \\
\text { Boşanmış }\end{array}$ & $\begin{array}{l}2(10,5) \\
13(68,4) \\
2(10,5) \\
2(10,5)\end{array}$ \\
\hline Sigara kullanımı & $\begin{array}{c}6(31,6) \\
13(68,4)\end{array}$ \\
\hline Alkol kullanımı & $\begin{array}{c}1(5,3) \\
18(94,7)\end{array}$ \\
\hline Kendine ait geliri & $\begin{array}{l}10(52,6) \\
9(47,4)\end{array}$ \\
\hline & XISS \\
\hline Yaş (yıl) & $38.42 \pm 13.65$ \\
\hline Vücut kütle indeksi $\left(\mathrm{kg} / \mathrm{m}^{2}\right)$ & $28.38 \pm 8.21$ \\
\hline Eğitim (yıl) & $10.68 \pm 4.17$ \\
\hline
\end{tabular}


Tablo 2. Bireylerin eğitim öncesi ve sonrası ağrı, yorgunluk şiddeti ve uyku sorununun karşılaştırılması

\begin{tabular}{|c|c|c|c|c|}
\hline & Gevşeme Eğitimi Öncesi & Gevşeme Eğitimi Sonrası & & \\
\hline GAS (0-10cm) & XISS & XISS & $\mathbf{z}$ & $\mathbf{p}$ \\
\hline Ağrı & $5.05 \pm 3.34$ & $1.89 \pm 2.20$ & $-2,710$ & $0,007^{*}$ \\
\hline Yorgunluk şiddeti & $6.21 \pm 2.57$ & $3.47 \pm 2.38$ & $-3,644$ & $0,001^{*}$ \\
\hline Uyku sorunu & $5.42 \pm 2.87$ & $2.68 \pm 2.10$ & $-3,537$ & $0,001^{*}$ \\
\hline
\end{tabular}

${ }^{*} \mathrm{p}<0,05$ GAS: Görsel Analog Skala

\section{TARTIŞMA}

Ruhsal hastalıklarda gevşeme eğitiminin ağrı, yorgunluk şiddeti ve uyku sorunu üzerine etkisinin incelenmesi amacıyla planlanan bu çalışmadan elde edilen veriler doğrultusunda tüm parametrelerde iyileşme görülmüştür.

Alkol ve madde kullanım bozuklukları en önemli halk sağlığı sorunlarından birisidir. En sık kullanılan maddelerin alkol ve nikotin olduğu görülmüştür. Ruhsal bozukluklarda yüksek oranlarda görülen alkol ve madde kullanım bozuklukları hastalık ve tedavi sürecini belirgin olarak etkilemektedir (Karakuş, Evlice ve Tamam, 2012). Bizim çalışmamızda katılımcıların alkol ve sigara kullanım oranının düşük olduğu görülmüştür. Bu durumun örneklem sayısının büyük olmaması ile ilgili olduğunu düşünmekteyiz. Sigara kullanımı ile ilişkili olan durumlardan biri de eğitim düzeyidir (Yılmaz ve Tarhan, 2016). Yüksek eğitim düzeyine sahip olan bireylerin daha az sigara tüketme eğiliminde oldukları belirtilmiştir (Yen, 2005; Kılıç, 2014; Yılmaz ve Tarhan, 2016). Çalışmamızda katıımcıların eğitim yılı ortalamalarına bakıldığında eğitim seviyelerinin yüksek olması ve sigara kullanma oranının düşük olması literatürle paralellik göstermektedir.

Damush ve arkadaşları (2016), depresyon bulgularına ek olarak ağrı sorunu olan olan bireylerde farmakolojik tedavi ile ağrı özyönetim müdahaleleri (örneğin; kuvvetlendirme-germe egzersizleri, ilerleyici kas gevşemesi ve görüntü imgeleme) uyguladıkları kontrollü çalışmalarında farmakolojik tedaviyle birlikte öz yönetim yaklaşımlarının ağrı ve depresyon bulgularında olumlu etkileri olduğunu belirtmişlerdir. (Damush, Kroenke, Bair ve ark, 2016). Tse ve arkadaşları (2013), tarafından kronik ağrısı olan yaşlı bireylerde yapılan randomize kontrollü bir diğer çalışmada, motivasyonel görüşmeye ve gevşeme tekniklerini de içeren egzersiz programına katılan yaşlı bireylerin ağrı ve depresyon bulgularında iyileşme olduğu belirtilmiştir (Tse, Vong ve Tang, 2013). Gevşeme eğitiminin ameliyat sonrası akut ağrı kontrolünde de kullanıldığı çalışmada, gevşeme eğitimiyle ağrı şiddetinin azaldığı görülmüştür (Seers, Crichton, Tutton ve ark., 2008). Kavak ve arkadaşlarının 2015'te yaptığı çalışmada, şizofreni tanılı bireylerde gevşeme egzersizi ve müzik terapi uygulamasıyla katılımcıların psikolojik belirtilerinin yanı sıra ruhsal durumunda özellikle depresyon bulgularında iyileşme olduğu kanıtlanmıştır (Kavak, Ünal ve Yılmaz, 2015). Çalışmamızda da ruhsal hastalıkların yanı sıra ağrı sorunuyla da karşı karşıya kalmış katılımcılarımız gevşeme eğitimi ile birlikte ağrılarında azalma olduğunu ifade etmişlerdir ve katılımcıların düşüncesiyle istatistiksel olarak anlamlı çıkan sonuçlarımız örtüşmektedir. Literatürle paralellik gösteren çalışmamızda pek çok psikiyatrik vakada önemli bir sorun olan ve tedavi yaklaşımlarını olumsuz etkileyen ağrı ile mücadelede gevşeme eğitiminin önemi ortaya koyulmuştur.

Choi'nin (2010), bakım verenlere uyguladığı gevşeme eğitiminin anksiyete ve yorgunluk üzerine etkisini incelediği çalışmasında, anksiyete ve yorgunluğun önemli ölçüde azaldığı görülmüştür (Choi, 2010). Carletto ve arkadaşlarının (2017), multipl skleroz ile birlikte depresyon tanısı olan kişilerde vücut-etkili farkındalık müdahalesinin etkinliğini gevşeme teknikleri ve germe egzersizlerini içeren psiko-eğitimsel bir müdahale ile karşılaştırarak değerlendiren çalışmalarında depresyon, anksiyete ve yorgunluk bulguları incelenmiştir. Her iki müdahalenin de anksiyete ve depresif bulguları azaltmada benzer şekilde etkili olduğu ancak yorgunluğu iyileştirmediği belirtilmiştir (Carletto, Tesio, Borghi ve ark., 2017). Psikiyatrik hastaların aldıkları farmakolojik tedavi sonunda yorgunluk, motivasyonel düşüklük ve isteksizlik gibi durumlar ortaya çıkmaktadır. Katılımcılara uyguladığımız terapatik müzik eşliğindeki gevşeme eğitiminde sıralı gevşemeyle akıl ve beden uyumunu sağlayarak kişilerin daha fazla dinlenmeleri, günlük streslerden ve olumsuz düşüncelerden 
uzaklaşmaları sağlanmıştır. Elde edilen veriler doğrultusunda da gevşeme eğitimiyle yorgunluk bulgularında anlamlı şekilde azalma olduğu bulunmuştur.

Psikiyatrik hastalıklarda uyku sorunlarının oldukça sık görüldüğü bildirilmektedir (Stein, Belik, Jacobi ve ark., 2008). Çetinkaya (2013) ile Kwekkeboom ve arkadaşlarının (2012), gevşeme eğitiminin uyku sorunu üzerine etkilerini araştırdıkları çalışmalarında uyku kalitesini bozan etmenlerin başında anksiyete ve ağrı olduğunu belirlemişlerdir (Çetinkaya, 2013; Kwekkeboom, Abbott-Anderson, Cherwin ve ark., 2012). Çalışmamızda katılımcıların yarısından çoğunda hem ağrı hem de uyku sorunu bulunmaktaydı. Solunum tekniği, ilerleyici kas gevşeme ve postür eğitiminin ruhsal bozukluğu olan bireylerde ağrı ve uyku sorununun azaltılmasında önemli olduğunu düşünmekteyiz.

Rethorst ve arkadaşları (2013), majör depresyon bozukluğu olan katılımcılarda, farmakolojik tedavi yerine günlük aktivite olarak egzersizin uyku problemlerini önemli ölçüde iyileştirdiğini bulmuşlardır (Rethorst, Sunderajan, Greer ve ark., 2013). Yapılan çalışmalarda; farkındalık (mindfulness) uygulamaları, solunum egzersizi ve kognitif davranışsal terapinin kognitif temelli müdahalelerini alan katılımcıların uyku sorunlarında önemli bir iyileşme olduğu görülmüştür (Chan, Wong, Sze ve ark., 2012; Chien, Chung, Yeh ve ark., 2015; Hsu, Chou, Lin ve ark., 2015; Taylor, Rybarczyk, Nay ve ark., 2015). Neuendorf ve ark.'larının farkındalık (mindfulness) müdahalelerinin uyku kalitesi üzerine etkisini değerlendirmek amacıyla yaptıkları sistematik derlemede, gevşeme tekniklerinin uyku problemleri olan kişilerde daha iyi bir uyku kalitesi için faydalı olabileceğini vurgulamışlardır (Neuendorf, Wahbeh, Chamine ve ark., 2015). Depresyon bulgularına ek olarak uyku problemi olan katılımcılarda, kognitif davranışsal terapi ile gevşeme eğitiminin karşılaştırıldı̆ı çalışmada, her iki yaklaşımında depresif belirtiler üzerinde eşit etkiye sahip olduğu ancak kognitif davranışsal terapinin uykusuzluk şiddeti ve semptomları üzerinde daha büyük bir etkisi olduğu belirtilmiştir (Norell-Clarke, JanssonFröjmark, Tillfors ve ark., 2015). Çalışmamızda gevşeme eğitimiyle kasların gevşemesinin yanı sıra zihinde canlandırma da kullanılarak aynı zamanda zihinsel odaklanmayı sağlayıp katılımcıların daha fazla rahatlamaları ve sakinleşmeleri sağlanmıştır. Bu durumun ruhsal bozukluğa sahip bireylerde uyku sorununun anlamlı olarak azalmasında etkili olduğunu düşünmekteyiz.

Literatüre bakıldığında gevşeme eğitiminin kanser, multipl skleroz, göğüs hastalıkları gibi fiziksel hastalıklara sahip uyku problemi olan bireyler üzerinde de olumlu etkileri olduğu görülmüştür (Wright, Courtney ve Crowther, 2002; Simeit, Deck ve Marx, 2004; Dayapoğlu ve Tan, 2012; Mansel ve Carey, 2014; Nooner, Dwyer, DeShea ve ark., 2016; Yilmaz ve Kapucu, 2017). Ruhsal bozukluğu olan kişilerde uyguladığımız gevşeme eğitiminin katıımcıların uyku sorunu üzerinde iyileştirici etkilerinin olması olumlu sonuçları desteklemektedir. Bu sonuçlarla gevşeme eğitiminin diğer yaklaşımlar ve farklı hasta gruplarında olduğu gibi ruhsal hastalıklara sahip bireylerde de uyku sorunu üzerine olumlu etkileri olduğu bulunmuştur.

Katıımcılar aynı eğitimi evde uyguladıklarında, seanslardaki kadar verimli geçmediğini, terapist varlığındaki eğitimi daha doğru yaptıklarını belirtmişlerdir. Çalışmamızın kısıtıııkları arasında dâhil edilen kişi sayısının az olması, tanı grubunun çeşitli ruhsal hastalıkları içermesi, kontrollü bir desenin olmaması, depresyon bulgusunun, ruhsal bozukluk şiddetinin ve tedaviye yanıtının değerlendirilmemesi sayılabilir.

Sonuç olarak, ruhsal hastalıklara sıklıkla eşlik eden ve bireyi olumsuz yönde etkileyebilen ağrı, yorgunluk ve uyku problemleri üzerine odaklanmak psikiyatrik bakımda tedavi kalitesini artırmak açısından önemlidir. Solunum tekniği ile ilerleyici kas gevşeme ve postür eğitiminin müdahale planları içerisinde yer almasının yararlı olabileceği görülmüştür. Bu olumlu bulgulara rağmen, kontrol grubunun olduğu, verilen eğitimin uzun süreli takibinin yapıldığı ve daha fazla sayıda katılımcının dâhil edildiği ileri çalışmalara intiyaç vardır.

\section{Kaynaklar}

Alan, H. (2015). Jinekolojik Kanser Hastalarında Kemoterapi Tedavisi Sürecinde Uygulanan Progresif Kas Gevşeme Egzersizleri ve Refleksolojinin Ağrı, Yorgunluk, Anksiyete, Depresyon ve Yaşam Kalitesi Üzerine Etkisi; Randomize Kontrol Çalışması (Yayınlanmamış Doktora Tezi). Hacettepe Üniversitesi Doğum ve Kadın Hastalıkları Hemşireliği Programı, Ankara.

Arslan, M., \& Özdemir, L. (2015). Kemoterapiye bağlı gelişen bulantı-kusmanın yönetiminde kullanılan tamamlayıcı tedavi yöntemleri. Türk Onkoloji Dergisi, 30(2),82-89. https://doi.org/10.5505/tjoncol.2015.1204

Aydın, A., Araz, A., \& Asan, A. (2011). Görsel Analog Ölçeği ve duygu kafesi: kültürümüze uyarlama çalışması. Türk Psikoloji Yazıları, 14(27), 1-13.

Aydın, B., \& İmamoğlu, S. (2001). Stresle başa çıkma becerisi geliştirmeye yönelik grup çalışması. Eğitim Bilimleri 
Dergisi, 14(14), 41-52.

Bozhüyük, A., Özcan, S., Kurdak, H., Akpınar, E., Saatçı, E., \& Bozdemir, N. (2012). Sağlıklı yaşam biçimi ve aile hekimliği. Turkish Journal of Family Medicine and Primary Care, 6(1), 13-21.

Can, S. (2013). Kamu personeli seçme sınavı nedeniyle öğretmen adaylarında oluşan stresle başa çıkma yöntemleri. Education Sciences, 8(1), 27-45.

Carletto, S., Tesio, V., Borghi, M., Francone, D., Scavelli, F., Bertino, G., \& et al. (2017). The effectiveness of a bodyaffective mindfulness intervention for multiple sclerosis patients with depressive symptoms: a randomized controlled clinical trial. Front Psychol, 8, 1-13. https://doi.org/10.3389/fpsyg.2017.02083

Chan, A. S., Wong, Q. Y., Sze, S. L., Kwong, P. P. K., Han, Y. M. Y., \& Cheung, M. C. (2012). A chinese chanbased mind-body intervention improves sleep on patients with depression: a randomized controlled trial. Sci World J, 110. https://dx.doi.org/10.1100/2012/235206

Chien, H. C., Chung, Y. C., Yeh, M. L., \& Lee, J. F. (2015). Breathing exercise combined with cognitive behavioural intervention improves sleep quality and heart rate variability in major depression. J Clin Nurs, 24, 32063214. https://doi.org/10.1111/jocn.12972

Choi, Y. K. (2010). The effect of music and progressive muscle relaxation on anxiety, fatigue, and quality of life in family caregivers of hospice patients. J Music Ther, 47(1), 5369. https://doi.org/10.1093/jmt/47.1.53

Çelebi, M. M. (2016). Spor hekimliğinin ruh sağlığını koruma ve iyileştirmedeki rolü: multidisipliner yaklaşım-fiziksel değerlendirme-egzersiz reçeteleri. Türkiye Klinikleri $J$ Sports Med-Special Topics, 2(2), 59-64.Çetinkaya F. (2013). Progresif Gevşeme Egzersizlerinin Total Kalça Protezi Ameliyatı Olan Hastaların Uyku Kalitesine Etkisi (Yayınlanmamış Doktora Tezi). Atatürk Üniversitesi Sağlık Bilimleri Enstitüsü, Erzurum.

D’Amico, M. L., Jaffe, L. E., \& Gardner, J. A. (2018). Evidence for interventions to improve and maintain occupational performance and participation for people with serious mental illness: a systematic review. Am J Occup Ther, 72(5), 7205190020p1-7205190020p11. https://doi.org/10.5014/ajot.2018.033332

Damush, T. M., Kroenke, K., Bair, M. J., Wu, J., Tu, W., Krebs, E. E., \& Poleshuck, E. (2016). Pain self-management training increases self-efficacy, self-management behaviours and pain and depression outcomes. Eur $J$ Pain, 20(7), 1070-1078. https://doi.org/10.1002/ejp.830

Dayapoğlu, N., \& Tan, M. (2012). Evaluation of the effect of progressive relaxation exercises on fatigue and sleep quality in patients with multiple sclerosis. $J$ Altern Complement Med, 18(10), 983-987. https://doi.org/10.1089/acm.2011.0390

Durukan, E., İlhan, M. N., Bumin, M. A., \& Aycan, S. (2011). 2 hafta-18 aylık bebeği olan annelerde postpartum depresyon sıklığı ve yaşam kalitesi. Balkan Med J, 2011(4), 385-393. https://doi.org/10.5174/tutfd.2010.04117.3

Dünya Sağlık Örgütü (DSÖ); Ruhsal bozukluklar, http://www.who.int/topics/mental_disorders/en/ ; DSÖ, 2017, Erişim tarihi:10.01.2019

Ekici, G., Çelenay, Ş. T., \& Büyükturan, Ö. (2017). Investigation of the risk factors of diabetic neuropathy in terms of pain, sleep and quality of life. Turk J Physiother
Rehabil, 28(1), 27-32.

Ergül, A. (2012). Çalışma Yaşamında Stresin Bireysel Performans Üzerindeki Etkileri: Eğitim ve Sağlık Çalışanlarına Yönelik Bir Araştırma (Yayınlanmamış Yüksek Lisans Tezi). Balıkesir Üniversitesi Sosyal Bilimler Enstitüsü, Balıkesir.

Genç, A., \& Oğuz, S. (2018). Kanserli hastalarda progresif gevşeme egzersizlerinin kemoterapinin yan etkileri üzerine etkisi. İstanbul Gelişim Üniversitesi Sağlık Bilimleri Dergisi, 5, 517-524.

Gültekin, B. K. (2010). Ruhsal bozuklukların önlenmesi: kavramsal çerçeve ve sınıflandırma. Psikiyatride Güncel Yaklaşımlar, 2(4), 583-594.

Hasson, D., \& Arnetz, B. B. (2005). Validation and findings comparing VAS vs. Likert scales for psychosocial measurements. International Electronic Journal of Health Education, 8, 178-192.

Hsu, H. M., Chou, K. R., Lin, K. C., Chen, K. Y., Su, S. F.,\& Chung, M. H. (2015). Effects of cognitive behavioral therapy in patients with depressive disorder and comorbid insomnia: A propensity score-matched outcome study. Behav Res Ther, 73, 143-150. https://doi.org/10.1016/j.brat.2015.07.016

Jensen, M., Fayers, P.M., Haugen, D.F., Caraceni, A., Hanks, G.W., Loge, H.H., \& et al. (2011). Studies comparing numerical rating scales, verbal rating scales, and visual analogue scales for assessment of pain intensity in adults: a systematic literature review. European Palliative Care Research Collaborative (EPCRC), EUROPE, 41(6), 1073193. https://doi.org/10.1016/j.jpainsymman.2010.08.016

Karakuş, G., Evlice, Y. E., \& Tamam, L. (2012). Psikiyatri kliniğinde yatan hastalarda alkol ve madde kullanım bozukluğu sıklığı. Cukurova Medical Journal, 37(1), 3748.

Kavak, F., Ünal, S., \& Yılmaz, E. (2015). Şizofreni hastalarında gevşeme egzersizi ve müzik terapinin psikolojik belirtiler ve depresyon düzeyine etkisi. Integratif Tıp Dergisi, 3(2), 116-117.

Kılıç, D . (2014). Sigara tüketiminin panel veri analizi: İngiltere için bir uygulama. Gazi Üniversitesi Iktisadi ve Idari Bilimler Fakültesi Dergisi, 16 (3), 128-142.

Körükcü, Ö. \& Kukulu, K. (2015). Beden-zihin-ruh bütünlüğünü korumaya yönelik bir program: farkındalık temelli stres azaltma programı. Psikiyatride Güncel Yaklaşımlar, 7(1), 68-80.

Kurt, B., \& Akbaba, M. (2018). Çukurova yöresinde kırsal bir bölgedeki yetişkinlerin ruh sağlığı durumu ve etkileyen faktörler. Sakarya Tıp Dergisi, 8(3), 538-550.

Kwekkeboom, K. L., Abbott-Anderson, K., Cherwin, C., Roiland, R., Serlin, R. C., \& Ward, S. E. (2012). Pilot randomized controlled trial of a patient-controlled cognitive-behavioral intervention for the pain, fatigue, and sleep disturbance symptom cluster in cancer. J Pain Symptom Manage, 44(6), 810-822. https://doi.org/10.1016/j.jpainsymman.2011.12.281

Mansel, J. K., \& Carey, E. C. (2014). Nonpharmacologic approach to sleep disorders. The Cancer Journal, 20(5), 345-351. https://doi.org/10.1097/PPO.0000000000000066

Matcham, F., Rayner, L., Hutton, J., Monk, A., Steel, C., \& Hotopf, M. (2014). Self-help interventions for symptoms of depression, anxiety and psychological distress in patients with physical illnesses: a systematic review and meta- 
analysis. Clin Psychol Rev, 34(2), 141-157. https://doi.org/10.1016/j.cpr.2014.01.005

Neuendorf, R., Wahbeh, H., Chamine, I., Yu, J., Hutchison, K. \& Oken, B. S. (2015). The effects of mind-body interventions on sleep quality: a systematic review. EvidBased Compl Alt, 2015 http://dx.doi.org/10.1155/2015/902708

Nooner, A. K., Dwyer, K., DeShea, L., \& Yeo, T. P. (2016). Using relaxation and guided imagery to address pain, fatigue, and sleep disturbances: a pilot study. Clin J Oncol Nurs, 20(5), 547-553. https://doi.org/ 10.1188/16.CJON.547-552

Norell-Clarke, A., Jansson-Fröjmark, M., Tillfors, M., Holländare, F., \& Engström, I. (2015). Group cognitive behavioural therapy for insomnia: effects on sleep and depressive symptomatology in a sample with comorbidity. Behav Res Ther, 74, 80-93. https://doi.org/10.1016/j.brat.2015.09.005

Ocaktan, M. E., Özdemir, O., \& Akdur, R. (2004). Birinci basamakta ruh sağlığı hizmetleri. Kriz Dergisi, 12(2), 6373

Ohnhaus, E. E., \& Adler, R. (1975). Methodological problems in the measurement of pain: a comparison between the verbal rating scale and the visual analogue scale. Pain 1(4), 379-384. https://doi.org/10.1016/03043959(75)90075-5

Otman, A. S., \& Köse, N. (2006). Egzersiz Tedavisinde Temel Prensipler ve Yöntemler. Ankara: Meteksan AŞ.

Rethorst, C. D., Sunderajan, P., Greer, T. L., Grannemann, B. D., Nakonezny, P. A., Carmody, T. J., et al. (2013). Does exercise improve self-reported sleep quality in nonremitted major depressive disorder? Psychol Med, 43, 699-709. https://doi.org/10.1017/S0033291712001675

Sağbaş, Ö. (2009). Ruhsal Bozukluklarda Stresle Baş Etme Ve Yaşam Kalitesi (Yayımlanmamış Yüksek Lisans Tezi). Haliç Üniversitesi Sağlık Bilimleri Enstitüsü, İstanbul.

Seers, K., Crichton, N., Tutton, L., Smith, L., \& Saunders, T. (2008). Effectiveness of relaxation for postoperative pain and anxiety: randomized controlled trial. $J$ Adv Nurs, 62(6), 681-688. https://doi.org/ doi: 10.1111/j.13652648.2008.04642.

Simeit R., Deck R., Marx CB. (2004). Sleep management training for cancer patients with insomnia. Support Care Cancer, 12(3),176-183. https://doi.org/10.1007/s00520004-0594-5

Stein, M. B., Belik, S. L., Jacobi, F., \& Sareen, J. (2008). Impairment associated with sleep problems in the community: relationship to physical and mental health comorbidity. Psychosom Med, 70(8), 913-919. https://doi.org/10.1097/PSY.0b013e3181871405

T.C.Sağlık Bakanlığı (2011). Ulusal Ruh Sağığı Eylem Planı 2011-2023. T.C. Sağlık Bakanlığı, Ankara.

Taylor, H. L., Rybarczyk, B. D., Nay, W., \& Leszczyszyn, D.(2015). Effectiveness of a CBT intervention for persistent insomnia and hypnotic dependency in an outpatient psychiatry clinic. J Clın Psychol, 71, 666-683. https://doi.org/10.1002/jclp.22186

Tse, M. M., Vong, S. K., \& Tang, S. K. (2013). Motivational interviewing and exercise programme for communitydwelling older persons with chronic pain: a randomised controlled study. J Clın Nurs, 22(13-14), 1843-1856. https://doi.org/10.1111/j.1365-2702.2012.04317.x
Wright, S., Courtney, U., \& Crowther, D. (2002). A quantitative and qualitative pilot study of the perceived benefits of autogenic training for a group of people with cancer. Eur J Cancer Care, 11(2), 122-130. https://doi.org/10.1046/j.1365-2354.2002.00307.x

Yen, S. T. (2005). Zero observations and gender differences in cigarette consumption. Appl Econ, 37(16), 1839-1849. https://doi.org/10.1080/00036840500214322

Yilmaz, C. K., \& Kapucu, S. (2017). The effect of progressive relaxation exercises on fatigue and sleep quality in individuals with COPD. Holist Nurs Pract, 31(6), 369-377. https://doi.org/10.1097/HNP.0000000000000234

Yilmaz, T., \& Tarhan, P. (2016). Gebelikte sigara kullanımı ve etkileyen faktörler. Sağlık Bilimleri ve Meslekleri Dergisi, 3(3), 140-147. https://doi.org/ 10.17681/hsp.61635 